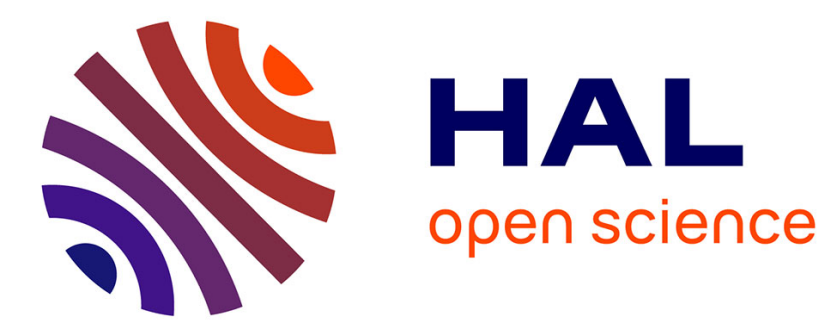

\title{
Cross-scale inference and wavefront reconstruction
}

\author{
Suman Kumar Maji, Thierry Fusco, Hussein Yahia
}

\section{To cite this version:}

Suman Kumar Maji, Thierry Fusco, Hussein Yahia. Cross-scale inference and wavefront reconstruction. SPIE Astronomical Telescopes + Instrumentation, Jun 2014, Montréal, Canada. SPIE, 2014, Adaptive Optics Systems IV (Conference 9148). hal-00951787

\section{HAL Id: hal-00951787 https://hal.inria.fr/hal-00951787}

Submitted on 16 Apr 2015

HAL is a multi-disciplinary open access archive for the deposit and dissemination of scientific research documents, whether they are published or not. The documents may come from teaching and research institutions in France or abroad, or from public or private research centers.
L'archive ouverte pluridisciplinaire HAL, est destinée au dépôt et à la diffusion de documents scientifiques de niveau recherche, publiés ou non, émanant des établissements d'enseignement et de recherche français ou étrangers, des laboratoires publics ou privés. 


\section{SPIE,}

A novel solution method using multiscale and nonlinear signal processing is proposed for the reconstruction of a turbulent phase in $A O$. Instead of using classical inverse problem formulations $[1,2,3]$, we make use of advanced nonsear and miteiscale analysis methods in signal processing for reconstructing Multiscale Formalism (MMF), which is a geometric approach to multifractality. Firstly. geometrically localized singularity exponents and important parameters are computed for atmospheric turbulence. We then design a methodology, based on precise computation of the SEs [4], by which optimal inference across the scales of a turbulent phase is made possible, and we show it can be used to reconstruct a (a)

\section{Multifractal systems in a Microcanonical Formulation (MMF)}

$\mathfrak{E}_{1}(\mathbf{x})$ : scale-dependent functional. Signal $\mathrm{s}$ is multifractal in a microcanonical sense [5]: for at least one functional $\mathfrak{E}_{1}(\mathrm{x})$

$$
\mathfrak{E}_{\mathbf{l}}(\mathbf{x})=\alpha(\mathbf{x}) \mathbf{l}^{h(\mathbf{x})}+o\left(\mathbf{l}^{h(\mathbf{x})}\right) \quad(\mathbf{l} \rightarrow 0)
$$

Exponent $h(\mathbf{x})$ : singularity exponent at point $\mathbf{x}$. In practical application:

$$
\mathfrak{E}_{1}(\mathbf{x})=\int_{\mathcal{B}(\mathbf{x}, 1)}\|\nabla \mathbf{s}\|(\mathbf{y}) \mathrm{d}(\mathbf{y})
$$

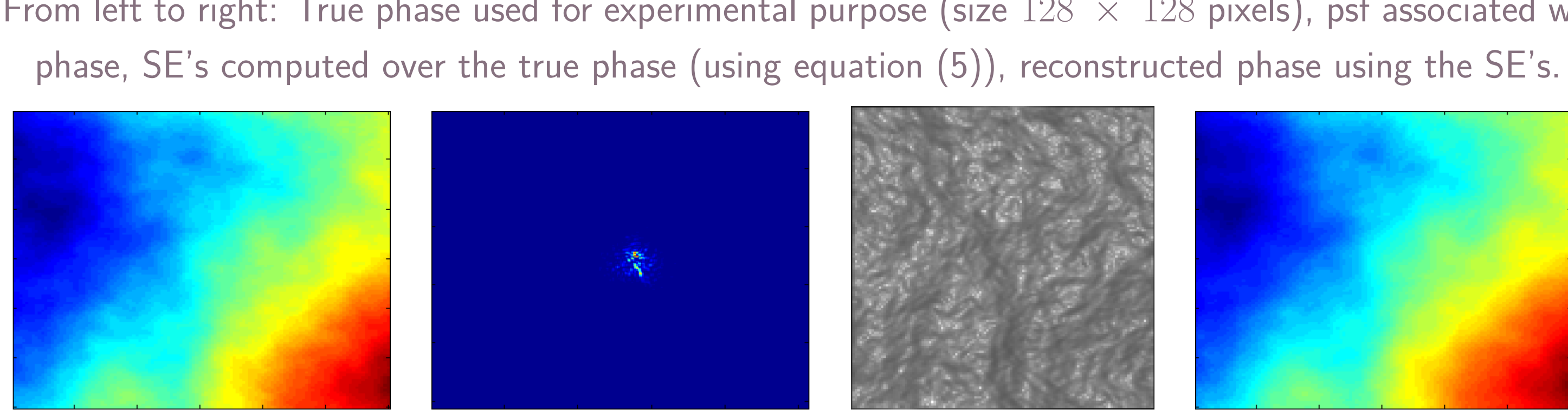

\section{Singularity analysis}

Multifractal hierarchy:

$$
\mathcal{F}_{h}=\{\mathbf{x}: h(\mathbf{x})=h\}
$$

econstruction using our technique is much better than the $L S$ estimator, especially in the case of very low-level SNR's.

Figure 2. Results of the reconstruction in a nobs animonment. Top row. Reconstructed phase under different levels of mage plane irradience and the $x$-axis corresponds to the angular distance in arseconds. Top row : The X cut of the ps

et $\mathcal{T}_{\mathbb{I}}\left(\mathfrak{E}_{1}(\mathrm{x})\right)$ be the wavelet projection of $\mathfrak{G}_{(\mathrm{x})}$ with mother wavelet

$$
\mathcal{T}_{\Psi}\left(\mathfrak{E}_{\mathbf{1}}(\mathbf{x})\right)=\frac{1}{\mathbf{l}^{2}} \int_{\mathbb{R}^{2}}\|\nabla \mathbf{s}\|(\mathbf{y}) \Psi\left(\frac{\mathbf{x}-\mathbf{y}}{\mathbf{l}}\right) \mathrm{d}(\mathbf{y})
$$

$$
h(\mathbf{x})=\frac{\log \left(\mathcal{T}_{\Psi}\left(\mathfrak{E}_{1}(\mathbf{x})\right) /\left\langle\mathcal{T}_{\Psi}\left(\mathfrak{E}_{1}(\cdot)\right)\right\rangle\right)}{\log \mathbf{1}}+o\left(\frac{1}{\log 1}\right)
$$

Results

Reconstruction has been done for 1000 phase-screens provided by ONERA, with gradients of three different sizes $(16 \times 16$ pixels, $32 \times 32$ pixels and $64 \times 64$ pixels respectively). We then calculate the residual phase for all the 1000 reconstructed phases and compute the average power spectral density with the LS estimator. The results clearly show the superiority of our algorithm with the classical LS estimator, under different levels of SNR (the residual phase error being less in our case). We repeat the same operation with cases where we take the SE's computed over an average instance of the true phase and a fixed FFT based Kolmogorov phase. We can see on figures that the overall performance of the
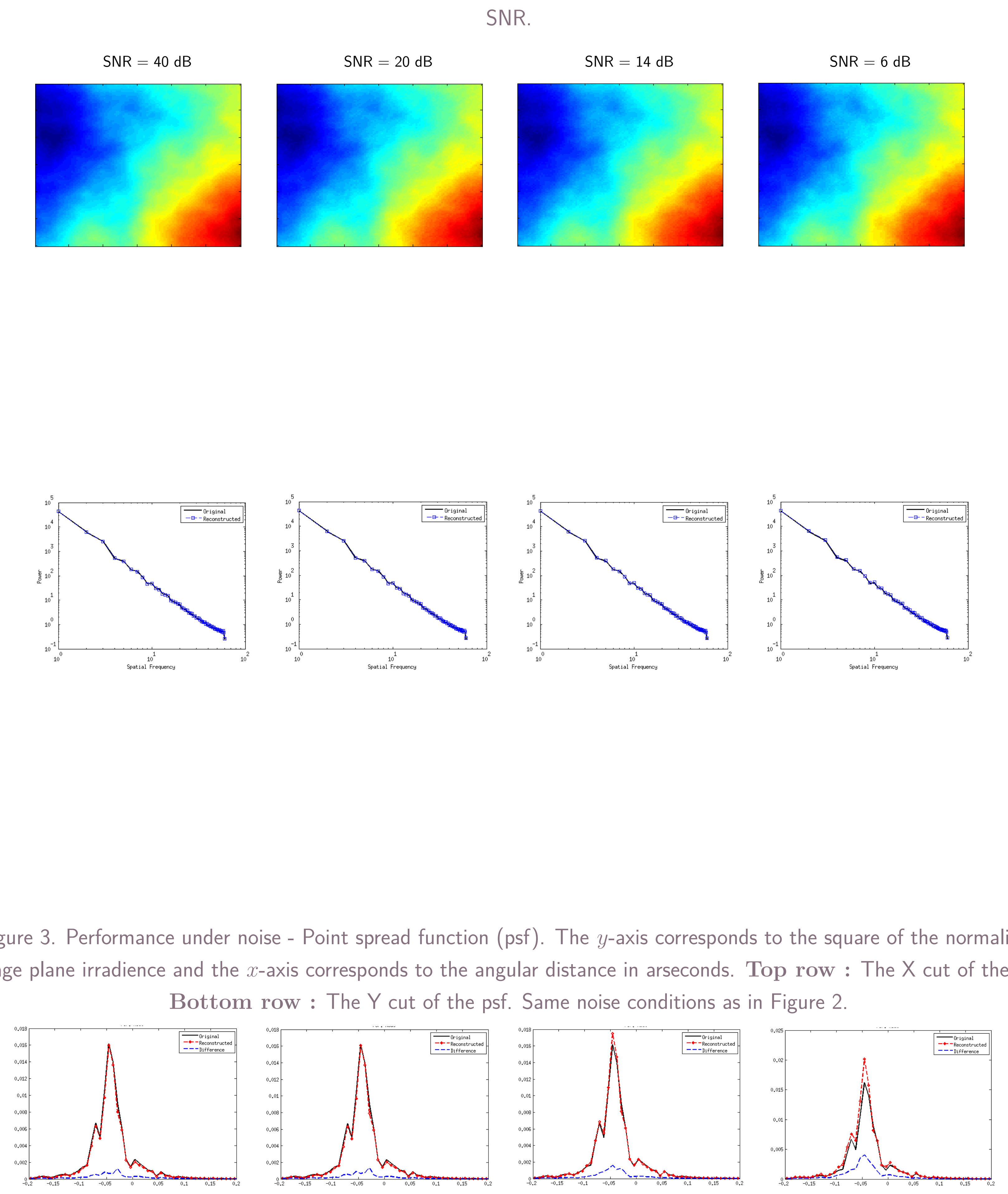

Figure 4. Comparison of the residual phase statistics with classical operators under level of SNR: 6dB. To estimate $\phi$ using the Mhi fechinue, we use the singularity exponents computed over the average phase instance (obtained by process of our algorithm
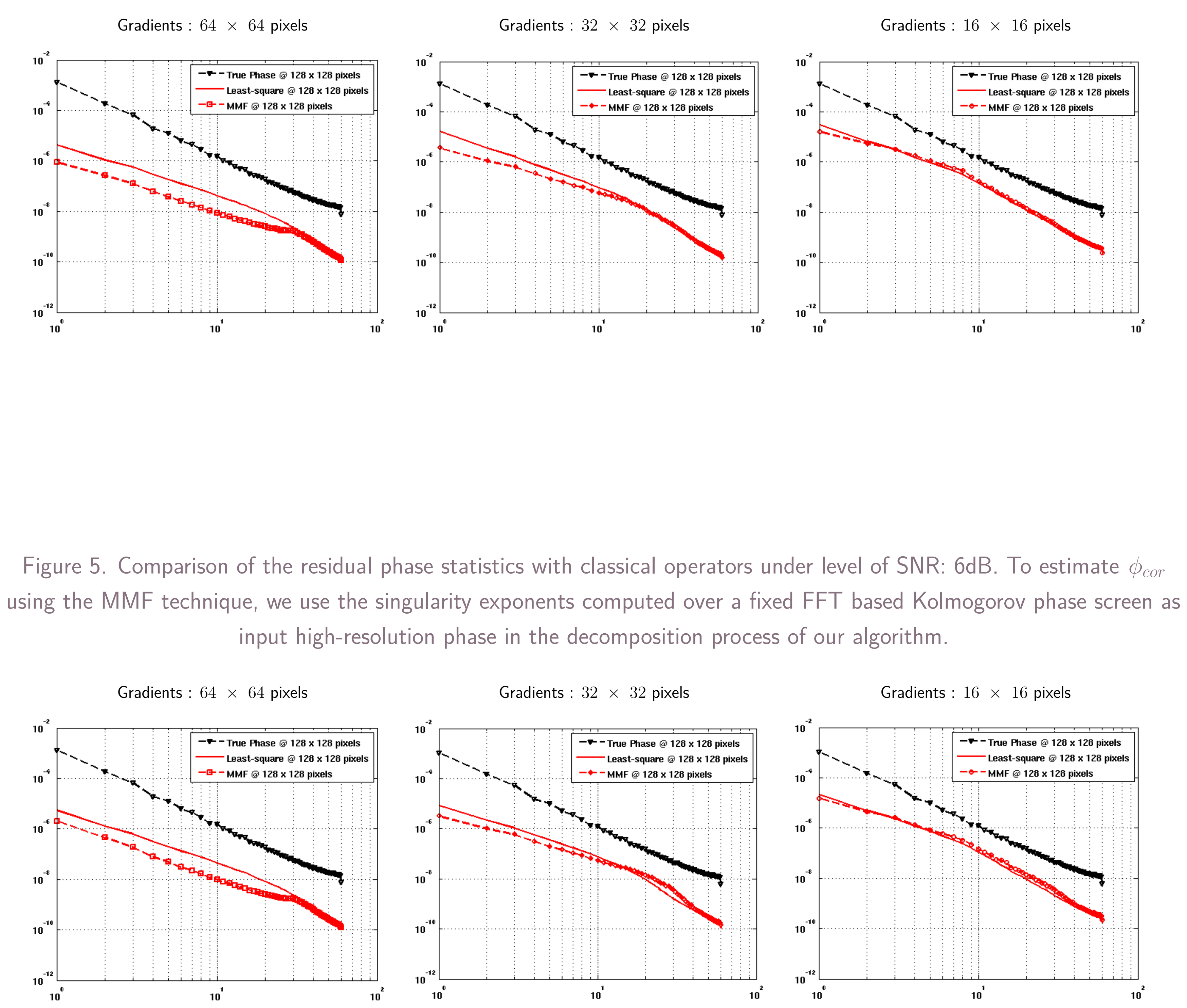

Acknowledgment and references

Suman Kumar Maji's PhD is funded by a CORDIS grant and Région Aquitaine OPTAD research project

\section{References}

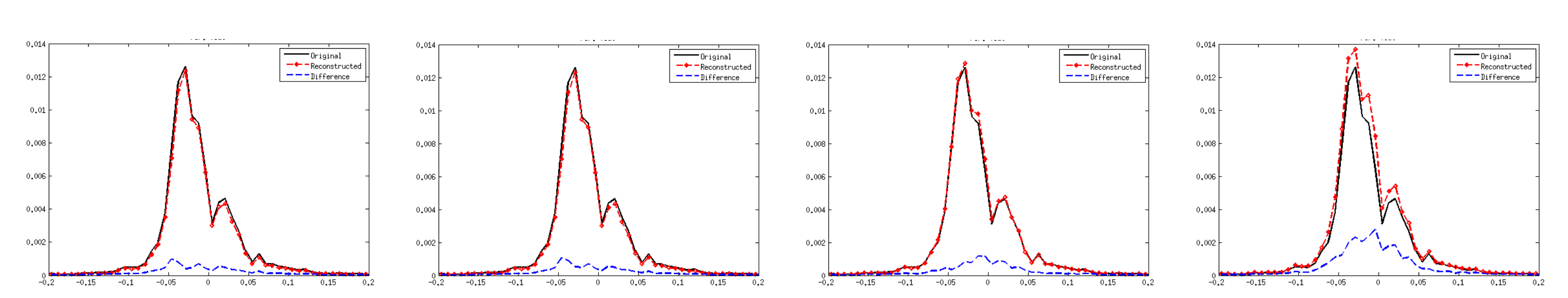

[1] Bardsley, J. M., "Wavefront reconstruction methods for adaptive optics systems on ground-based telescopes," SIAM J. Matrix Analysis Applications 30, 67-83 (2008).

(2) Mugnier, L., Besnerais, G. L., and Meimon, S. Inversion in optical ind turbulence in Bayesian approach to inverse problems], Jérôme Idier ed., ISTE, John Wiley \& Sons Inc. (2008). ISBN: 878-1-84821-032-5.

[3] Gilles, L., Vogel, C. R., and Ellerbroek, B. L., "A multigrid preconditioned conjugate gradient method for large scale wavefront reconstruction," J. Opt. Soc. Am. A 19, 1817-1822 (2002).

[4] Turiel, A., Pérez-Vicente, C. J., and Grazzini, J., "Numerical methods for the estimation of multifractal singularity spectra on sampled data: A comparative study," Journal of Computational Physics 216, 362-390 (2006).

5] Maji, S. K. and Yahia, H., "Edges, transitions and criticality," Pattern Recognition, Elsevier 47 ,
$2104-2115$ (2014). 